\title{
4 \\ Health, Social, and Psychological Consequences of Drug Use and Abuse
}

\author{
Michael D. Newcomb and Thomas Locke
}

1. Introduction 46

2. Defining the Role of Drug Use 47

3. Methodological Issues 48

3.1. Criteria of Association 48

3.1.1. Short-Term Consequences 48

3.1.2. Long-Term Consequences 48

3.2. Additional Methodological Issues 49

4. Selective Review of Drug Use Consequences 50

4.1. Health 50

4.2. Mental Health $\quad 51$

4.3. Antisocial Behavior $\quad 53$

4.4. Interpersonal Relationships $\quad 54$

4.4.1. Impact on Adult Parenting Practices $\quad 54$

4.4.2. Workplace $\quad 55$

5. Conclusions 56

References $\quad 56$

MICHAEL D. NEWCOMB • University of Southern California

THOMAS LOCKE • University of California, Los Angeles 


\section{INTRODUCTION}

Several epidemiological researchers have begun a theoretical integration of the rather rich drug use and abuse etiology literature and the far less developed and somewhat paltry drug use and abuse consequences research findings. This integration has numerous advantages as well as theoretical and methodological challenges (Newcomb, 2004). It is beyond this chapter to delineate this synergy in much detail. However, the central focus of this approach is to consider drug use and abuse as mediators. A mediator is operationalized as a "generative mechanism through which the focal independent variable is able to influence the dependent variable of interest" (Baron and Kenny, 1986, P. 1173). Therefore, mediators (drug use and abuse) are predicted by various risk and protective factors. Also, they themselves are the predictors of later consequences and outcomes.

The underlying assumptions of drug use prevention programs are that their interventions will somehow reduce or eliminate the presumed adverse consequences related to drug use. Because of the intense focus on preventing drug use, funding and support for studies of the consequences of drug use has been minimal. By preventing drug use and abuse the wide spread adverse and devastating consequences of drug use both proximally (immediately) and distally (later in life) will also be prevented. Most in the field believe that drug abuse has many assumed catastrophic consequences for the individual, their friends and family, and society. Some supportive evidence exists. For instance, drug use during adolescence appears to have both short-term and long-term effects on cognitive and brain functioning (Brown et al., 2000; White, 2004). Yet there is a dearth of scientific evidence to firmly establish what these adverse consequences are, what mechanisms are involved, and how they might present in various psychosocial domains.

As a result, consequence components and related theoretical aspects of prevention programs may be targeting too many domains, omitting others, and thereby may be mis-directed. Accurate and realistic information on the consequences of drug ingestion is important not only for prevention and for treatment programming but also for making policy addressing the health, social and psychological needs of drug abusers.

Although not typically conceived of as such, the Diagnostic and Statistical Manual of Mental Disorders - $4^{\text {th }}$ Edition (American Psychiatric Association, 1994) diagnostic criteria are largely based on consequences of drug ingestion or the pursuit of the substance. Examples of these include, "important social, occupational, or recreational activities are given up or reduced because of substance use" and "the substance use is continued despite knowledge of having a persistent or recurrent physical or psychological problem that is likely to be caused or exacerbated by the substance..." (p. 181). Syndromes associated with substance intoxication and with withdrawal are also described. However, drug use that does not reach the level of severe psychosocial impairment is not necessarily considered. Therefore, 
there is an implication that drug use that does not meet the DSM-IV criteria for substance-use disorders is acceptable and does not promote adverse consequences.

Overall, research that focuses on drug using populations has shown that the consequences of drug use affect many areas of an individual's life. Some of the noted biological consequences include various areas such as HIV transmission and acquisition, neuro-cognitive impairment, heart disease, intergenerational transmission of biological predisposition, mortality/morbidity, and health-service utilization. Psychological consequences can include many domains such as mood disorders, anxiety, other psychiatric disorders, and disruption in adaptive coping mechanisms, attachment disruption, anger management, and suicidal ideation. Social domains that are often implicated include marital and relationship satisfaction, employment stability and satisfaction, educational attainment, legal issues/criminal behavior, parenting, and social support. However, the study of both long- and short-term consequences is challenged, primarily as assignment of the attribution of the impact of drug using behaviors is not always clear. There are two components to the assignment of attribution. The first relates to whether the consequences of drug use are direct, indirect or the result of the drug mediating or moderating of another process that is taking place. The second relates to the methodological difficulties of establishing causation.

\section{DEFINING THE ROLE OF DRUG USE}

Drug use consequences can be thought of as relating to three main processes: direct, indirect, and mediating/moderating effects. Direct effects vary across different developmental periods and are related to the specific influence of a drug on later outcome biopsychosocial functioning. Indirect effects are related to the influence of another person's drug use (parents, peers, partners) on the individual's life (e.g., psychological distress due to a partner's drug use). Indirect effects emphasize the importance of a systemic or holistic point of view. Finally, drug use can serve as a factor that alters other processes that may already be in play. Studying drug use as a moderator investigates how it "affects the relationship between two variables, so that the nature of the impact of the predictor on the criterion varies according to the level or value of the moderator (also see Saunders, 1956; Zedeck, 1971). Further, a moderator interacts with a predictor variable in such a way as to have an impact on the level of a dependent variable" (Holmbeck, 1997, p. 600). This can be represented in questions such as ... Can drug use exacerbate the effects of a poor upbringing? As a mediator, drug use is viewed as a "generative mechanism through which the focal independent variable is able to influence the dependent variable of interest" (Baron and Kenny, 1986, P. 1173). This process can be represented in questions such as ... Does drug use influence the relationship between early experience and later development? 
Appropriate, new, and innovative statistical methods can help estimate unique variance due to drug use/abuse when not accounted for by other competing independent variables. For instance, structural equation modeling allows for the simultaneous estimation of multiple independent variables with an approximation of variance explained and unexplained by each on given outcome variables. This is a way to maximize causal inference and try to account for or estimate the influence the specific and unique influence of drug use on different aspects of later psychosocial functioning.

\section{METHODOLOGICAL ISSUES}

Numerous methodological issues exist that make consequence research challenging. These issues are critical to consider in testing for and establishing the consequences of drug use. These include difficulty with operational definitions, research design, and the samples used.

\subsection{Criteria of Association}

Criteria to establish a direct relationship between drug use and "consequences" include: 1) a process, issue, or psychosocial outcome whose existing state or pre-morbid condition changes because of drug use; 2) the change in these outcomes is subsequent to drug use; 3 ) these outcomes would not change in the same way without the use of $\operatorname{drug}(\mathrm{s})$ (Newcomb, 1994); and 4) these consequences are not due to factors other than drug use. Further, it is important to conceptualize drug use consequences as being immediate or short-term, intermediate, and long-term (Newcomb, 1997).

\subsubsection{Short-Term Consequences}

Short-term consequences of drug use are relatively easy to establish through true experimental designs. For instance, establishing the direct physiological affect of a substance such as alcohol on reaction time can be accomplished with this method. Other more innovative approaches have also been developed such as the balanced placebo design (Marlatt et al., 1988). In this design, the expectancy effects of using a drug can be separated from the true pharmacological effects of the drug. Other more naturally occurring tragic short-term consequences include overdoses, car crashes due to alcohol or other drugs, and increased aggression and confrontational acts.

\subsubsection{Long-Term Consequences}

Long-term drug use consequences are far more difficult to establish than are those that are considered short-term. The primary reason for this is that true 
experimental control over the types of drugs used and the duration of their use is not possible. Therefore, it is difficult to establish how such use influences functioning later in life. For instance, it is not ethical to randomly assign one group of sixth graders to smoke one joint of marijuana every day and another matched group of sixth graders to never smoke marijuana to determine how the two groups differ in their level of functioning later in life. Therefore the only alternative is to follow the naturally unfolding development of individuals over time and repeatedly assess their drug use and their evolving biopsychosocial maturation.

In order to establish causal inferences for long-term drug use consequences four assumptions must be met. First, there must be a reliable association between drug use and the outcome or consequence. Second, drug use must temporally precede the consequence. Third, the drug use must make a change in the consequence. Using both baseline and outcome measures of the consequence to show that drug use contributes unique variance above and beyond the specific stability effect. Finally, it is important to show that these relationships are not spurious and due to third-variable factors. This final assumption is not always possible to satisfy, and represents an inherent limitation in consequence research. However, using complex multivariate models that explicitly include alternate predictors of the outcomes is a powerful, but still not definite, approach to use to determine the plausible causal inferences of drug use on later consequences.

\subsection{Additional Methodological Issues}

Several additional points are important to mention as a backdrop for this discussion. First, it is important to consider that consequences may be different for quantity of drug use versus frequency of drug use (Stein et al., 1988). Second, short-term consequences of drug use may have their own unique long-term effects, which may or may not be the same long-term consequences of the use of the drug alone. Third, since the use of one or more substances is relatively common, using a statistical method that can tease-out the specific effects of the use of a particular substance from the general effect of polydrug use is important (Newcomb, 1994). Fourth, consequences of substance use result from cumulative use, may respond to a change (increase or decrease) in substance use, or may occur once a particular threshold of use is crossed. Finally, consequences of drug use are different at different ages (Newcomb and Jack, 1995). For instance, alcohol use as a teenager may predict educational drop-out but stronger social skills and positive self concept (Newcomb and Bentler, 1988), whereas as a young adult it may predict poor parenting skills later in life (Locke and Newcomb, 2004).

In addition to methodological limitations regarding research design, another consideration relates to the nature of the samples used in consequence research. Much of existing research uses treatment or clinical samples. People within these samples typically have more serious problems with substances, and may very well have additional psychosocial conditions which may impair their functioning. 
Applying information obtained from these samples to the community at large has inherent problems.

\section{SELECTIVE REVIEW OF DRUG USE CONSEQUENCES}

Many short-term and long-term consequences of drug use have been investigated. This section reviews and categorizes findings in three broad areas, health consequences, psychological consequences, and social consequences. Since these domains encompass such a wide range of topics and human behaviors, this review is not exhaustive. Rather, specific areas within each domain are selectively reviewed. The review on health consequences includes HIV-sexual risk behaviors, healthservice utilization, and morbidity/mortality statistics. The section on psychological consequences focuses on suicidality, depression, anxiety, and psychosis. The section on social consequences is focused on interpersonal relationships. Specifically, antisocial behavior (theft and violent crime), interpersonal relationships (marital satisfaction, divorce, parenting), and workplace involvement (absenteeism, job satisfaction and stability) will be reviewed. Since both short-term and long-term consequences are important to consider, both cross-sectional and prospective studies are included in the following review.

\subsection{Health}

Various short-term health consequences associated with drug use have been established (over-doses, aggression, accidents). Long-term consequences have been more difficult to adequately test as the physiological mechanisms are more difficult to determine. The use of cigarettes is associated with cancer, emphysema, and heart disease. Cigarette smoking is responsible for over 400,000 deaths per year. Alcohol use is responsible for over 400,000 alcohol-related traffic crash deaths per year and over 25,000 people die from cirrhosis of the liver (National Institute on Alcohol Abuse and Alcoholism, 2004). Illicit drug use is associated with many health consequences including death (suicide, homicide, motor-vehicle injury) HIV infection, pneumonia, violence, and hepatitis. Overall, it is estimated that illicit drug use resulted in approximately 17,000 deaths in 2000 (Mokdad et al., 2004).

Drug abuse is often an important determinant or correlate of sexual risk behaviors (Tapert et al., 2001; Testa and Collins, 1997). Drugs are used to enhance the sexual experience or the engagement in sexual behaviors helps to support the costs of drugs. Drug use has consistently been found to significantly increase sexual and other risk behaviors in many diverse populations. For instance, in a large community-based sample of male Latinos, Locke et al., (in press) found that drug 
use predicted more partners, more pregnancies, and more HIV testing. Further, another study (Newcomb et al., 2003) found that drug use mediated the influence of physical and emotional abuse on sexual risk behaviors in a large community sample of Latinas. Overall, behavior associated with drug abuse is now the single largest factor in the spread of HIV infection in the United States. In the United States, an estimated one-third of HIV/AIDS cases are related to injecting drug use. The use of drugs injected or not, can affect decision making-particularly about engaging in unsafe sex-that can endanger one's health and the health of others (National Institute on Drug Abuse, 2003).

Ellickson et al., (2004) studied the adult behavioral, socioeconomic, and health outcomes of adolescent and young adult marijuana users in a large prospective community sample. They identified several groups of individuals: those who abstained from marijuana use, early high users, stable light users, steady increasers, and occasional light users. Growth mixture analysis was conducted on six-waves of data on marijuana users collected over a 10-year period. After controlling for gender, race-ethnicity, household composition, and parental education, they found that the early high users had significantly poorer overall health than all other groups. Further, they had significantly lower earnings and lower educational attainment than all but the stable light users. Abstainers outperformed all other groups by age 29 in the domains of educational achievement, overall health, and life satisfaction.

Those who abuse drugs often have higher levels of health service utilization than those who do not (Newcomb and Bentler, 1987). Palepu et al., (2003) examined emergency department utilization in a longitudinal study of HIV-infected persons with a history of alcohol problems. They found that substance abuse treatment was significantly related to decreased emergency room visits. However, the effect may be different for different substances, and may not be entirely linear. Cherpitel (2003) examined health service utilization in the US using two large national surveys conducted in 1995 and 2000. It was found that those reporting any health services utilization were less likely to report heavy drinking, two or more alcohol problems, and symptoms of alcohol dependence. Heavy or problem drinking was not predictive of health services utilization. After controlling for demographic characteristics and health insurance coverage, illicit drug users were almost twice as likely compared with nonusers, to report ER utilization, and one and a half times more likely to report primary care utilization in the 2000 survey, even though drug use was not significantly predictive of health services utilization in 1995.

\subsection{Mental Health}

A few longitudinal studies have examined the mental health consequences of drug use in general community populations, and varied findings have emerged (e.g., 
Kandel et al., 1986; Newcomb and Bentler, 1987; 1988). Some have reported causal relationships between drug use and deteriorated emotional health (e.g., Dackis and Gold, 1983; Newcomb and Bentler, 1987; 1988). Vaillant's (1995, 1993) highly cited, yet controversial study of male college students yields some interesting findings. He found that those who abused alcohol were five times more likely to report being severely depressed than those who did not. Vaillant's assertion that alcoholism is rarely the result of depression, but it is often a major causative factor, supports other views in the literature (e.g., Schuckitt, 1986), but it is disconcerting that he based this on such a small sample $(\mathrm{N}=14)$. Further, while this is considered a community study, it is of males from Harvard University and therefore is not representative of the college-aged population. Overall, though accepted as common knowledge, evidence for causal relationships between early drug use and later deficits in emotional development is "hard to verify scientifically" (Newcomb and Bentler, 1988, p. 64). For example, adequate controls for preexisting conditions and important confounds may not have been made.

Another longitudinal prospective study found a reciprocal effect between substance involvement and psychological distress (dysphoria and suicidal ideation), with substance use serving as both a predictor and outcome of psychological distress. Specifically, Newcomb et al., (1999) found that as an individual progressed through adulthood, psychological functioning was impaired by substance problems experienced four years earlier. In addition, they found that substance involvement was influenced by earlier psychological distress. Christoffersen et al., (2003) also found that suicide risk was associated with prior drug addiction in a prospective register-based study of Danish children.

Newcomb et al., (1993) used prospective data from a community sample of 487 participants who were assessed 4 times over 12 years, beginning when they were young adolescents. They found that teenage polydrug use had few direct or unique effects on adult mental health, whereas increased polydrug use exacerbated later psychoticism, suicide ideation, and other indicators of emotional distress. Specific drug use in adolescence and changes in usage patterns into young adulthood predicted later psychopathology. Pencer and Addington (2003) also found that substance use was related to higher positive psychotic symptoms.

Locke and Newcomb (2001) found several reciprocal relationships between alcohol use and dysphoria for both men and women over a 16-year period from adolescence to adulthood. For women, dysphoria during young adulthood had serious consequences, leading to alcohol-related problems and use of alcohol at work during adulthood. Also, alcohol involvement in young adulthood led to specific aspects of dysphoria in adulthood. For men, alcohol involvement during late adolescence led to depression as measured by the CES-D in adulthood, and depression scale scores in late adolescence led to alcohol involvement in adulthood. Also, suicidal ideation during late adolescence predicted use of alcohol at work in adulthood. 
In a longitudinal study of adolescents, Shedler and Block (1990) found that those who had engaged in some drug experimentation were the best-adjusted of all participants. Those who frequently used drugs were maladjusted, and displayed interpersonal alienation, poor impulse control, and manifest emotional distress. If an adolescent had not experimented with any drug by age 18, they were relatively anxious, emotionally constricted, and lacking in social skills. Further, several studies have reported apparently positive effects from moderate alcohol use, including greater positive affect, stress reduction, and limited improvements in cognitive performance (Baum-Baicker, 1985; Kandel et al., 1986; Newcomb and Bentler, 1987, 1988; Newcomb et al., 1986).

\subsection{Antisocial Behavior}

Although there is a clear correlation between drug use and criminality, several problems contribute to uncertainty as to how they are causally related in the general population. First, a focus on only clinical samples (e.g., Hanlon et al., 1990), adults in the criminal justice system (Harrison, 1992; Innes and Greenfeld, 1990), or adolescent samples (e.g., Apospori et al., 1995) limits the generalizability of the results to community samples of adults. Nevertheless, the association between drug abuse and criminal behavior and delinquency in the general population has been examined (e.g., Kaplan, 1995). Second, cross-sectional data prohibit the elucidation of the causal relation between drug abuse and criminal behavior. Third, many previous studies have examined specific types of drug use and not polydrug use, which might more likely be related to criminal behavior as it suggests a more deviant lifestyle of drug abuse. Therefore, whether drug problems precede criminality or criminal behaviors precede drug problems continues to be debated (Kaplan and Damphousse, 1995). Finally, the potential influence of other contributing or explanatory factors, such as social support and social conformity, have received little attention.

Brook et al. (2003) tested associations between marijuana use and several domains of behavior 2 years later in a community-based sample of 1,151 male and 1,075 female Colombian adolescents. Findings suggest that time 1 adolescent marijuana use was associated with increased risks for time 2 adolescent difficulty in a variety of domains including violent experiences. The findings suggest that early adolescent marijuana use is associated with an increase in problem behavior during later adolescence.

Newcomb et al. (2001) used prospective data to test the associations between drug abuse and crime in a community sample of 470 adults. Polydrug problems in early adulthood predicted both criminal behavior and polydrug problems in adulthood. Consequences of drug problems as a young adult included arrests and convictions for drug-related offenses, property damage, and driving under the influence of other drugs. Predictors of later polydrug problems included thefts, 
driving under the influence of alcohol and other drugs, arrests and convictions for drug-related offenses, and a lack of support for drug problems. Theoretical implications of these findings are discussed.

\subsection{Interpersonal Relationships}

The two key consequence areas relative to interpersonal relationships that have been studies are parenting practices and workplace behaviors.

\subsubsection{Impact on Adult Parenting Practices}

"The presence of substance abuse in an adult may or may not be an indicator that he or she is a dysfunctional parent" (Mayes, 1995 p. 101). Most work involving the influence of drug use on parenting looks at treatment or clinical samples. A few community studies have found associations between drug use and poor parenting. Newcomb and Loeb (1999) found poor parenting to be associated with a cluster of adult deviant behaviors that included polydrug problems and crime. Overall, it appears that drug-using parents are more likely to live unconventional lifestyles and endorse nonconventional values, and these values influence their role and functioning as parents (Kandel, 1990). For instance, substance using parents have displayed poor parenting skills, provided inadequate supervision of their children, and disciplined their children in a lax or coercive manner (Vaillant and Milofsky, 1982).

The relationships between alcohol use and relational quality are well documented. For instance, high levels of family dysfunction are related to alcohol use (McKay et al., 1992), and alcoholic couples have been characterized by interpersonal violence (Quigley and Leonard, 2000) and sexual dissatisfaction (O'Farrell et al., 1997). Spouses of alcoholics expressed greater dissatisfaction in all areas of family functioning than alcoholics (Suman and Nagalakshmi, 1995). This dissatisfaction may be reflected in the finding that both marital dissatisfaction and divorce rates are as much as seven times greater in alcoholics than the general population (Schafi et al., 1975). Medora and Woodward (1991) studied loneliness in alcoholics, finding significant negative relationships between the number of years alcohol was consumed and self-esteem, marital satisfaction, and loneliness. The relationship between alcohol use and relationship satisfaction may not be entirely linear. Under some circumstances, alcohol use has adaptive consequences (Steinglass, 1981) and has been associated with increased marital satisfaction. For example, Jacob et al. (1983) found that high alcohol consumption was associated with high levels of marital satisfaction in the spouses of steady drinkers, but not binge drinkers. An indirect effect or consequence of drug use may be difficulty in intimate relationship functioning among adult children of drug-using parents. Newcomb and Rickards (1995) found that parent drug-use problems predicted 
poor family support, and family support was strongly associated with good adult intimate relations for both men and women. Furthermore, for men, more parent drug-use problems reduced dyadic adjustment, increased dependence, and had a specific effect on reducing dating competence. For women, parent drug-use problems had no direct effects on adult intimacy or relationship variables.

\subsubsection{Workplace}

A large percentage of people in the workforce drink. Data from the National Household Survey on Drug Abuse (SAMHSA, 1998) indicated that almost 64\% of full-time employed adults (26-34 years old) used alcohol in the past month. Those who use alcohol heavily are more likely to have increased absenteeism, and to have had at least three employers in the last year (SAMHSA, 1997). Several relationships have been found between alcohol use and employment. Those who endorse an escapist drinking style drink more alcohol in response to work stress (Grunberg et al., 1999). Moderate levels of consumption are associated with increased income, while heavy drinking may be detrimental to income levels (Mullahy and Sindelar, 1992). It is often hypothesized that alcoholics would have a less stable pattern of employment due to the adverse consequences of heavy drinking. In fact, failure to fulfill major role obligations (work, school, and home) is a criterion (DSM-IV) for alcohol abuse. The direct association between alcohol use and the hours/weeks worked, length of employment and/or job loss specifically due to drinking problems has not been widely studied (Mullahy and Sindelar, 1992). Low job satisfaction has been shown to be associated with alcoholism (Hingson et al., 1981). Galaif et al. (2001) found that polydrug problems were both predictors and consequences of work adjustment. Individuals abusing drugs were more likely to experience an erratic job pattern, less likely to adhere to societal norms, experience a less satisfying career, and have smaller support networks.

Overall, mixed results have been found regarding the association between drug use and work adjustment. Some investigations have documented inconsistent work histories, unemployment, work stress, absenteeism, tardiness, low quality work, job instability, work performance problems, and problems with job satisfaction among drug and alcohol users (Ames and James, 1987; Kandel, et al., 1986; Newcomb, 1988). Others have not found adverse effects on work adjustment (e.g., unemployment, job satisfaction, work performance) as a result of substance use (Bachman et al., 1984; Newcomb, 1988). Still, some researchers dispute the belief that drug use is a serious problem in the workplace (Newcomb, 1994b).

Tam et al. (2003) found that childhood adversity experiences were precursors to later alcohol and drug use in a sample of homeless adults. Subsequently, regular substance use was negatively associated with labor force participation and social service utilization. 


\section{CONCLUSIONS}

Understanding and documenting both the short-term and long-term consequences of drug use and abuse are not as simple as it would appear. Drug use is intertwined with other norm-violating behaviors and attitudes (McGee and Newcomb, 1992) and it is difficult to disentangle consequences unique to drug use from aspects of general deviance (Newcomb, 1994). Further, drug use is only one influence that shapes and alters personal development. In fact, it is only one discrete component of the myriad biopsychosocial forces that forge a human being. Many of these may be far more potent and important than drug use in the evolving development and resulting outcome and qualities of a person and their life.

Disclaimer. This research was funded by grant DA 01070 from the National Institute on Drug Abuse.

\section{REFERENCES}

American Psychiatric Association (1994). Diagnostic and Statistical Manual of Mental Disorders, Fourth Edition. American Psychiatric Association, Washington, D.C.

Ames, G. M. and James, C. R. (1987). Heavy and problem drinking in an American blue collar population: Implications for prevention. Social Science and Medicine 25, pp. 949-960.

Apospori, E. A., Vega, W. A., Zimmerman, R. S., Warheit, G. J., and Gil, A. G. (1995). A longitudinal study of the conditional effects of deviant behavior on drug use among three racial/ethnic groups of adolescents. In: H. B. Kaplan (Ed.), Drugs, Crime, and Other Deviant Adaptations: Longitudinal Studies (pp. 211-230). Plenum, New York.

Bachman, J. G., O’Malley, P. M., and Johnston, L. D. (1984). Drug use among young adults: The impacts of role status and social environment. Journal of Personality and Social Psychology 47, pp. 629-645.

Baum-Baicker, C. (1985). The psychological benefits of moderate alcohol consumption: A review of the literature. Drug and Alcohol Dependence 15, pp. 305-322.

Baron, R. M., and Kenny, D. A. (1986). The moderator-mediator variable distinction in social psychological research: Conceptual, strategic, and statistical considerations. Journal of Personality and Social Psychology 51(60), pp. 1173-1182.

Brook, J. S., Brook, D. W., Rosen, Z., and Rabbitt, C. R. (2003). Earlier marijuana use and later problem behavior in Colombian youths. Journal of the American Academy of Child and Adolescent Psychiatry 42, pp. 485-492.

Brown A.S., Tapert S.F., Granholm E, and Delis D.C. (2000). Neurocognitive functioning of adolescents: effects of protracted alcohol use. Alcohol Clinical and Experimental Research 24, pp. 164171.

Centers for Disease Control and Prevention (2003). HIV/AIDS among African Americans (online): http://www.cdc.gov/hiv/pubs/Facts/afam.htm.

Cherpitel, C. J. (2003). Changes in substance use associated with emergency room and primary care services utilization in the United States general population: 1995-2000. American Journal of Drug and Alcohol Abuse 29(4), pp. 789-802.

Christoffersen, M. N., Poulsen, H. D., and Nielsen, A. (2003). Attempted suicide among young people: Risk factors in a prospective register based study of Danish children born in 1966. Acta Psychiatrica Scandinavica 108(5), pp. 350-358. 
Dackis, C. A. and Gold, M. S. (1983). Opiate addiction and depression-cause or effect? Drug and Alcohol Dependence 11, pp. 105-109.

Ellickson, P. L., Martino, S. C., and Collins, R. L. (2004). Marijuana use from adolescence to young adulthood: Multiple developmental trajectories and their associated outcomes. Health Psychology 23(3), pp. 299-307.

Galaif, E. R., Newcomb, M. D., and Vargas-Carmona, J. (2001). Prospective relationships between drug problems and work adjustment in a community sample of adults. Journal of Applied Psychology 86, pp. 337-350.

Grunberg, L., Moore, S., Anderson-Connolly, R., and Greenberg, E. (1999). Work stress and selfreported alcohol use: The moderating role of escapist reasons for drinking. Journal of Occupational Health Psychology 4(1), pp. 29-36.

Hanlon, T. E., Nurco, D. N., Kinlock, T. W., and Duszynski, K. R. (1990). Trends in criminal activity and drug use over an addiction career. American Journal on Alcohol Abuse 16, pp. 223-238.

Harrison, L. D. (1992). Trends in illicit drug use in the United States: Conflicting results from national surveys. International Journal of the Addictions 27, pp. 817-847.

Hingson, R. T. Mangione, T., and Barrett, J. (1981). Job characteristics and drinking practices in the Boston metropolitan area. Journal of Studies on Alcohol 42, pp. 725-738.

Holmbeck, G. (1997). Toward terminological, conceptual, and statistical clarity in the study of mediators and moderators: Examples from the child-clinical and pediatric psychology literatures. Journal of Consulting and Clinical Psychology 65(4), pp. 599-610.

Innes, C. A., and Greenfeld, L. A. (1990). Violent State Prisoners And Their Victims (Special report). U.S. Department of Justice, Washington, D.C.

Jacob, T., Dunn, N. J., and Leonard, K. (1983). Patterns of alcohol abuse and family stability. Alcoholism: Clinical and Experimental Research 7(4), pp. 382-385.

Kandel, D. B. (1990). Parenting styles, drug use, and children's adjustment in families of young adults. Journal of Marriage and the Family 52, pp. 183-196.

Kandel, D. B., Davies, M., Karus, D., and Yamaguchi, K. (1986). The consequences in young adulthood of adolescent drug involvement. Archives of General Psychiatry 43, pp. 746-754.

Kaplan, H. B. (1995). Drugs, crime, and other deviant adaptations. In: H. B. Kaplan (Ed.). Drugs, Crime, and Other Deviant Adaptations: Longitudinal Studies (pp. 3-46). Plenum, New York.

Kaplan, H. B., and Damphousse, K. R. (1995). Self-attitudes and antisocial personality as moderators of the drug use-violence relationship. In: H. B. Kaplan (Ed.), Drugs, Crime, and Other Deviant Adaptations: Longitudinal Studies (pp. 187-210). Plenum, New York.

Locke, T. F., and Newcomb, M. D. (2001). Alcohol problems and dysphoria: A longitudinal examination of gender differences from late adolescence to adulthood. Psychology of Addictive Behaviors 15(3), pp. 227-236.

Locke, T. F., and Newcomb, M. D. (2004). Childhood maltreatment, parent drug problems, polydrug problems, and parenting practices: A test of gender differences and four theoretical perspectives. Journal of Family Psychology 18(1), pp. 120-134.

Locke, T. F., Newcomb, M. D., and Goodyear, R. K. (in press). Childhood experiences and psychosocial influences on risky sexual behavior, condom use, and HIV attitudes/behaviors among Latino males. Psychology of Men and Masculinity.

Marlatt, G. A., Baer, J. S., Donovan, D. M., and Kivlahan, D. R. (1988). Addictive behaviors: Etiology and treatment. Annual Review of Psychology 19, pp. 223-252.

Mayes, L. C. (1995). Substance abuse and parenting. In: M. H. Bornstein (Ed.), Handbook of Parenting, Vol. 4: Applied and Practical Parenting (pp. 101-125). Erlbaum, Mahwah, NJ.

Medora, N. P., and Woodward, J. C. (1991). Factors associated with loneliness among alcoholics in rehabilitation centers. Journal of Social Psychology 131(6), pp. 769-779.

McGee, L., and Newcomb, M. D. (1992). General deviance syndrome: Expanded hierarchical evaluations at four ages from early adolescence to adulthood. Journal of Consulting and Clinical Psychology 60 , pp. 766-776. 
McKay, J. R., Longabaugh, R. Beattie, M. C. Maisto, S. A., and Noel, N. E. (1992). The relationship of pretreatment family functioning to drinking behavior during follow-up by alcoholic patients. American Journal of Drug and Alcohol Abuse 18(4), pp. 445-460.

Mokdad, A. H., Marks, J. S., Stroup, D. F., and Gerberding, J. L. (2004). Actual causes of death in the United States, 2000. Journal of the American Medical Association 291(10), pp. 1238-1245.

Mullahy, J., and Sindelar, J. (1992). Effects of alcohol on labor market success: Income, earnings, labor supply and occupation. Alcohol Health and Research World 16(2):134-139.

The National Institute on Drug Abuse (NIDA) (2003, June). NIDA InfoFacts. http://www.drugabuse. gov/Infofax/DrugAbuse.html.

The National Institute on Alcohol Abuse and Alcoholism (NIAAA) (2004). NIAAA Quick Facts http:// www.niaaa.nih.gov/databases/qf.htm.

Newcomb, M. D. (1988). Drug Use in the Workplace: Risk Factors for Disruptive Substance Use Among Young Adults. Auburn House, Dover, MA.

Newcomb, M. D. (1994). Drug use and intimate relationships among women and men: Separating specific from general effects in prospective data using structural equations models. Journal of Consulting and Clinical Psychology 62, pp. 463-476.

Newcomb, M. D. (1994b). Prevalence of drug use in the workplace: Cause for concern or irrational hysteria? Journal of Drug Issues 24, pp. 403-416.

Newcomb, M. D. (1997). Psychosocial predictors and consequences of drug use: A developmental perspective within a prospective study. Journal of Addictive Diseases 16, pp. 51-89.

Newcomb M. D. (2004). Understanding Drug Use as a Developmental and Mediating Process: Theoretical Considerations and Empirical Examples. Paper presented at Beyond the Drug: APSAD 2004 National Conference. Perth, Australia.

Newcomb, M. D., Abbott, R. D., Catalano, R. F., Hawkins, J. D., Battin-Pearson, S. R., and Hill, K. (2002). Mediational and deviance theories of late high school failure: Process roles of structural strains, academic competence, and general versus specific problem behaviors. Journal of Counseling Psychology 49, pp. 172-186.

Newcomb, M. D., and Bentler, P. M. (1987). The impact of late adolescent substance use on young adult health status and utilization of health services: A structural equation model over four years. Social Science and Medicine 24, pp. 71-82.

Newcomb, M. D., and Bentler, P. M. (1988). Consequences of Adolescent Drug Use: Impact on the Lives of Young Adults. Sage Publications, Beverly Hills, CA.

Newcomb, M. D., Bentler, P. M. and Collins, C. (1986). Alcohol use and dissatisfaction with self and life: A longitudinal analysis of young adults. Journal of Drug Issues 16, pp. 479-494.

Newcomb, M. D., and Jack, L. E. (1995). Drug use, agency, and communality: Causes and consequences among adults. Psychology of Addictive Behaviors, pp. 967-982.

Newcomb, M. D., and Galaif, E. R., and Vargas-Carmona, J. (2001). The drug-crime nexus among a community sample of adults. Psychology of Addictive Behaviors 15, pp. 185-193.

Newcomb, M. D., and Locke, T. F., and Good year, R. K. (2003). Childhood experiences and psychosocial influences on HIV risk among adolescent Latinas in Southern California. Cultural Diversity and Ethnic Minority Psychology 9, pp. 219-235.

Newcomb, M. D., and Loeb, T. B. (1999). Poor parenting as an adult problem behavior: General deviance, deviant attitudes, inadequate family support/bonding, or just bad parents? Journal of Family Psychology 13, pp. 175-193.

Newcomb, M. D., and Rickards, S. (1995). Parent drug-use problems and adult intimate relations: Associations among community samples of young adult women and men. Journal of Counseling Psychology 42(2), pp. 141-154.

Newcomb, M. D., Scheier, L. M., and Bentler, P. M. (1993). Effects of adolescent drug use on adult mental health: A prospective study of a community sample. Experimental and Clinical Psychopharmacology 1, pp. 215-241. 
Newcomb, M. D., Vargas-Carmona, J. and Galaif, E. R. (1999). Drug problems and psychological distress among a community sample of adults: Predictors, consequences, or confound? Journal of Community Psychology 27, pp. 405-429.

O'Farrell, T. J., Choquette, K. A., Cutter, H., G., and Birchler, G. R. (1997). Sexual satisfaction and dysfunction in marriages of male alcoholics: Comparison with nonalcoholic martially conflicted and nonconflicted couples. Journal of Studies on Alcohol 58(1), pp. 91-99.

Palepu, A., Horton, N. J., Tibbetts, N., Dukes, K., Meli, S., and Samet, J.H. (2003). Substance abuse treatment and emergency department utilization among a cohort of HIV-infected persons with alcohol problems. Journal of Substance Abuse Treatment 25(1), pp. 37-42.

Pencer, A. and Addington, J. (2003). Substance use and cognition in early psychosis. Journal of Psychiatry and Neuroscience 28(1), pp. 48-54.

Quigley, B. M., and Leonard, K. E. (2000). Alcohol and the continuation of early marital aggression. Alcoholism: Clinical and Experimental Research 24(7), pp. 1003-1010.

Saunders, D. R. (1956). Moderator variables in prediction. Educational and Psychological Measurement 16 , pp. 209-222.

SAMHSA [Substance Abuse and Mental Health Service Administration] (1997). Worker Drug Use and Workplace Policies and Programs: Results from the 1994 and 1997 National Household Survey on Drug Abuse. US Government Printing Office, Washington, D.C.

SAMHSA [Substance Abuse and Mental Health Service Administration] (1998). National Household Survey on Drug Abuse: Main Findings 1992. US Government Printing Office, Washington, D.C.

Schafi, M., Lavely, R., and Jaffe, R. (1975). Medication and the prevention of alcohol abuse. American Journal of Psychiatry 132(9), pp. 942-945.

Schuckit, M. A. (1986). Genetic and clinical implications of alcoholism and affective disorder. American Journal of Psychiatry 143(2), pp. 140-147.

Shedler, J and Block, J. (1990). Adolescent drug use and psychological health: A longitudinal inquiry. American Psychologist 45(5), pp. 612-630.

Stein, J. A., Newcomb, M. D., and Bentler, P. M. (1988). Structure of drug use behaviors and consequences among young adults: A multitrait-multimethod assessment of frequency, quantity, worksite, and problematic substance use. Journal of Applied Psychology 73, pp. 595-605.

Steinglass, P. (1981). The alcoholic family at home: Patterns of interaction in dry, wet, and transitional stages of alcoholism. Archives of General Psychiatry 38(5) pp. 578-584.

Suman, L. N., and Nagalakshmi, S. V. (1995). Family interaction patterns in alcoholic families. NIMHANS Journal 13(1), pp. 47-52.

Tam, T. W., Zlotnick, C., and Robertson, M. J. (2003). Longitudinal perspective: Adverse childhood events, substance use, and labor force participation among homeless adults. American Journal of Drug and Alcohol Abuse 29(4), pp. 829-846.

Tapert, S. F., Aarons, G. A., Sedlar, G. R., and Brown, S. A. (2001). Adolescent substance abuse and sexual risk-taking behavior. Journal of Adolescent Health 28(3), pp. 181-189.

Testa, M. and Collins, R. L. (1997). Alcohol and risky sexual behavior: Event-based analyses among a sample of high-risk women. Psychology of Addictive Behaviors 11(3), pp. 190-201.

Vaillant, G. E. (1993). Is alcoholism more often the cause or the result of depression? Harvard Review of Psychiatry 1(2), pp. 94-99.

Vaillant, G. E. (1995). The Natural History of Alcoholism Revisited. Harvard University Press, Cambridge, MA.

Vaillant, G.E. and Milofsky, E.S. (1982). The etiology of alcoholism: A prospective viewpoint. American Psychologist 37, pp. 494-503.

White, A. M. (2004) http://www.duke.edu/ amwhite/index.html

Zedeck, S. (1971). Problems with the use of "moderator" variables. Psychological Bulletin 76, pp. 295 310 . 